\title{
Therapeutic Ultrasound Angioplasty: The Risk of Arterial Perforation. An In Vitro Study
}

\author{
Mark Wylie \\ Technological University Dublin, mark.wylie@tudublin.ie \\ Garrett McGuinness \\ Dublin City University \\ Graham Gavin \\ Technological University Dublin, graham.gavin@tudublin.ie
}

Follow this and additional works at: https://arrow.tudublin.ie/engschmanconn

Part of the Biomedical Engineering and Bioengineering Commons, and the Manufacturing Commons

\section{Recommended Citation}

Wylie, M., McGuinness, G., Gavin, G.: Therapeutic Ultrasound Angioplasty: The Risk of Arterial Perforation. An In Vitro Study. Proceedings of the 31st Engineering in Medicine and Biology Society, 2009. EMBS 2009. 31st Annual International Conference of the IEEE, pp.282-285. 2009.

This Conference Paper is brought to you for free and open access by the School of Manufacturing and Design Engineering at ARROW@TU Dublin. It has been accepted for inclusion in Conference Papers by an authorized administrator of ARROW@TU Dublin. For more information, please contact arrow.admin@tudublin.ie, aisling.coyne@tudublin.ie,gerard.connolly@tudublin.ie. Funder: Technology Sector Strand 1 


\title{
Therapeutic Ultrasound Angioplasty: The Risk of Arterial Perforation. An In Vitro Study
}

\author{
Mark P. Wylie, Garrett B. McGuinness, and Graham P. Gavin
}

\begin{abstract}
The use of therapeutic ultrasound delivered via small diameter wire waveguides may represent an emerging minimally invasive approach in the treatment of chronic total occlusions (CTOs), calcified and fibrous plaques. The distal-tip mechanical vibrations (typically 0-210 $\mu$ m peak-to-peak) have been reported to debulk rigid calcified and fibrous tissues while healthy elastic arterial tissue remains largely unaffected. The risk of arterial (healthy tissue) perforation with energized waveguides is not fully understood. An ultrasonic apparatus capable of delivering a range of wire waveguide distal-tip displacements, up to $80 \mu \mathrm{m}$ peak-to-peak (p-p), at an operational frequency of $22.5 \mathrm{KHz}(+/-6 \%)$ has been developed. For three distal-tip displacement settings $(32,50$ and $80 \mu \mathrm{m}$ p-p) with $1.0 \mathrm{~mm}$ diameter waveguides, the force required to perforate healthy porcine aortic tissue was experimentally determined.

The results show a distinct two stage perforation, thought to be the result of different mechanical properties of the layers in the arterial wall. The average maximum force $(\mathrm{N})$ required to cause perforation with the $1.0 \mathrm{~mm}$ diameter ultrasonic waveguide activated at the three settings was experimentally determined to be $2.7 \mathrm{~N}(32 \mu \mathrm{m}$ p-p), $2.6 \mathrm{~N}(50 \mu \mathrm{m}$ p-p) and $2 \mathrm{~N}$ $(80 \mu \mathrm{m}$ p-p). The force required to cause perforation of the tissue with no ultrasound was found to be approximately $4 \mathrm{~N}$. These results highlight that when ultrasound energy is applied to the waveguide, less force is required to perforate healthy arterial tissue. This reduction in perforation force is more pronounced at higher ultrasonic displacements, similar to those reported in clinical studies for the effective removal of diseased calcified and fibrous plaques.
\end{abstract}

\section{INTRODUCTION}

$\mathrm{C}$ ardiovascular diseases (CVDs) are the number one cause of death globally [1]. Atherosclerosis is an intimal lesion that effects large and medium sized muscular arteries (such as coronary, iliac and femoral) and also large elastic arteries (such as aorta). It is a gradual chronic cardiovascular disease and is the most common cause of acute myocardial infarction [2], [3].

This disease begins with deposits of fatty substances

Manuscript received April 7, 2009. This work was supported by a grant warded under Ireland's Higher Education Authorities STRAND I scheme.

M.P. Wylie is a post-graduate research student in Dublin Institute of Technology's School of Manufacturing and Design Engineering, Dublin, Ireland. (e-mail: mark.wylie@dit.ie).

G.B. McGuinness is with Dublin City University's School of Mechanical and Manufacturing Engineering, Dublin, Ireland (e-mail: garrett.mcguinness@dcu.ie).

G.P. Gavin is with Dublin Institute of Technology's School of Manufacturing and Design Engineering, Dublin, Ireland. (tel: +353 1 4023952; fax: +353 14023986 ; e-mail: graham.gavin@dit.ie). (lipoproteins), cholesterol and cellular waste on the arterial endothelium but may progress to a fibro-calcific plaque. The majority of atherosclerotic lesions can be treated by minimally invasive dilation procedures such as balloon angioplasty and stent implantation.

These procedures often require that the lesion is initially crossed by a guidewire, a thin wire that acts as a rail for the dilation catheter. Plaques resulting in a near or totally occluded artery are known as chronic total occlusions (CTOs) and are often associated with dense calcifications. They can be identified in approximately $20 \%$ of all patients undergoing angioplasty and are challenging to classic dilation procedures that require prior guidewire crossing [4]. The limitations of standard dilation procedures mentioned have propagated an intensive search for adjuncts to balloon angioplasty and alternative therapies [5]-[8].

One such approach involves the use of low frequency (20$45 \mathrm{kHz}$ ) high power therapeutic ultrasonic energy delivered via small diameter wire waveguides. This form of energy develops a longitudinal standing wave in the wire waveguide and can result in distal-tip displacements up to $210 \mu \mathrm{m}$ peakpeak (p-p). This type of minimally invasive surgery has gained regulatory approval in recent years (2007/8) in the United States and Europe for treatment of CTOs [9]. It is reported that this form of energy can be useful for the treatment of CTOs by disrupting and ablating rigid calcified and fibrous plaque tissue while the healthy elastic arterial tissue in the region remains largely unaffected [10].

Using ultrasound in this manner may affect plaque by a number of ablation or disruption mechanisms. Direct mechanical agitation, cavitation, acoustic streaming and pressure components have all been reported [11], [12].

While the effects of ultrasound on rigid calcified and fibrous tissues have been the focus of the majority of studies the impact that this form of energy delivery has on surrounding healthy tissue is less well known, including adverse effects such as the risk of arterial perforation.

Chikada [13] conducted a number of experiments on diseased and healthy tissue using a $2.5 \mathrm{~mm}$ probe at an operational frequency of $24 \mathrm{kHz}$. This study focused on the ablation and removal of diseased plaques and demonstrated incidents of perforation of the surrounding healthy tissue at greater distal-tip displacements. The forces required to perforate the various plaque types were not reported while probe dimensions and amplitudes were not representative of minimally invasive ultrasonic angioplasty devices. 
As part of this work, the goal was to experimentally determine the forces required to perforate healthy porcine aortic tissue using waveguide distal-tip geometries and displacements similar to those reported in clinical studies [9]-[13].

\section{Methodology}

\section{A. Ultrasonic Wire Waveguide Apparatus}

An experimental ultrasonic apparatus was developed that can transmit ultrasonic energy through $1.0 \mathrm{~mm}$ diameter Nickel-Titanium (NiTi) waveguides with rounded distal tips. The frequency of operation was experimentally determined, as part of previous work, to be $22.5 \mathrm{KHz}(+/-6 \%)$ with achievable distal tip displacements of between $0-100 \mu \mathrm{m}$ p depending on power input level [14],[15]. These ultrasonic displacement measurements were made with an optical microscope and vision analysis software.

\section{B. Experimental Rig Development}

A test rig capable of advancing the ultrasonic waveguide vertically in a controlled manner was designed and developed. The ultrasonic converter and acoustic horn were secured vertically to a stepper motor lead screw assembly. The waveguide could be advanced at constant feed-rates between 0.05 and $1.5 \mathrm{~mm} / \mathrm{s}$, controlled via a stepper drive card.

The rig facilitated the securing of tissue samples in a cantilever beam assembly which had a half-bridge temperature compensation strain gauge arrangement capable of determining the force applied on the sample. The beam and tissue were submerged in a $15 \mathrm{~L}$ thermostatic bath of water at $37{ }^{0} \mathrm{C}$. The programming environment and hardware used to control the various instruments and acquisition of data was LabView@ and National Instruments $@$ PCI6221 DAQ. A schematic of the experimental set up is shown below, see Figure 1.

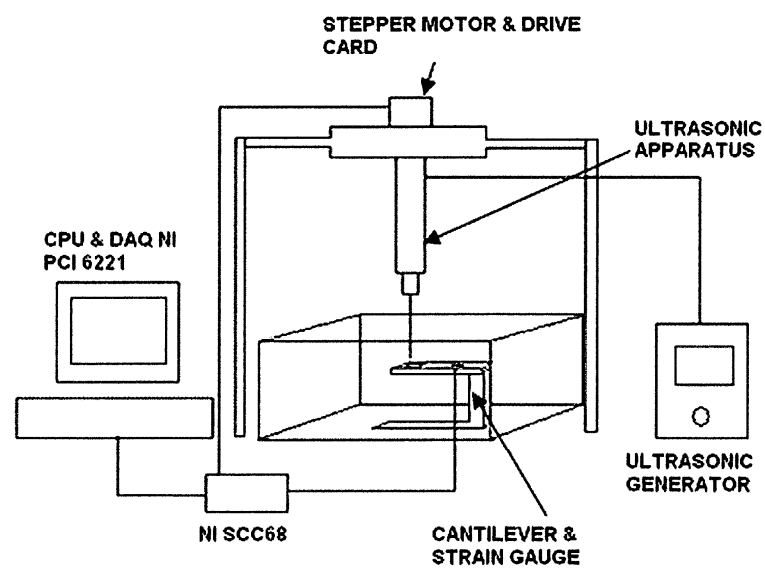

Fig. 1. Schematic of experimental rig with ultrasonic angioplasty apparatus, cantilever arrangement, thermostatic tank and data acquisition environment

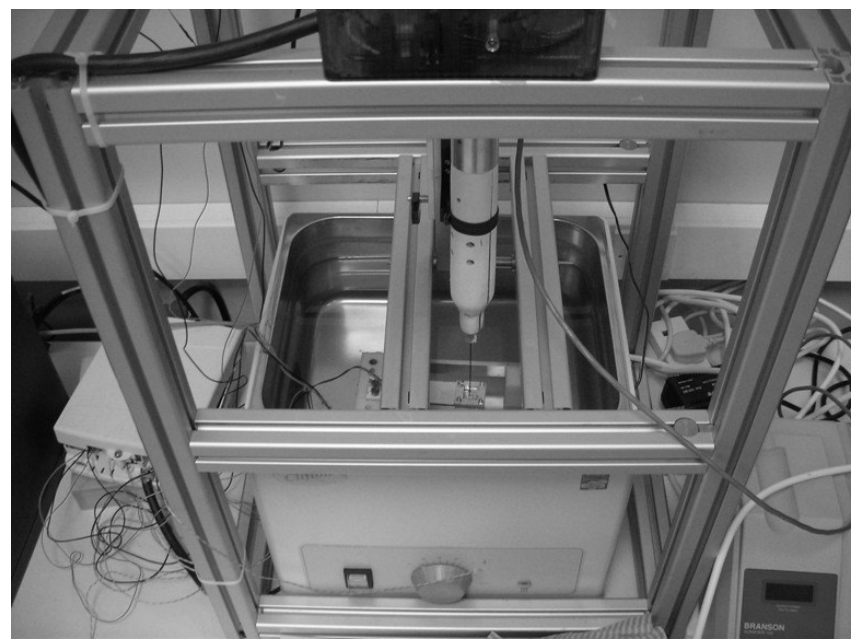

Fig. 2. Picture of experimental rig for tissue testing using ultrasound transmitted via NiTi wire wave guides.

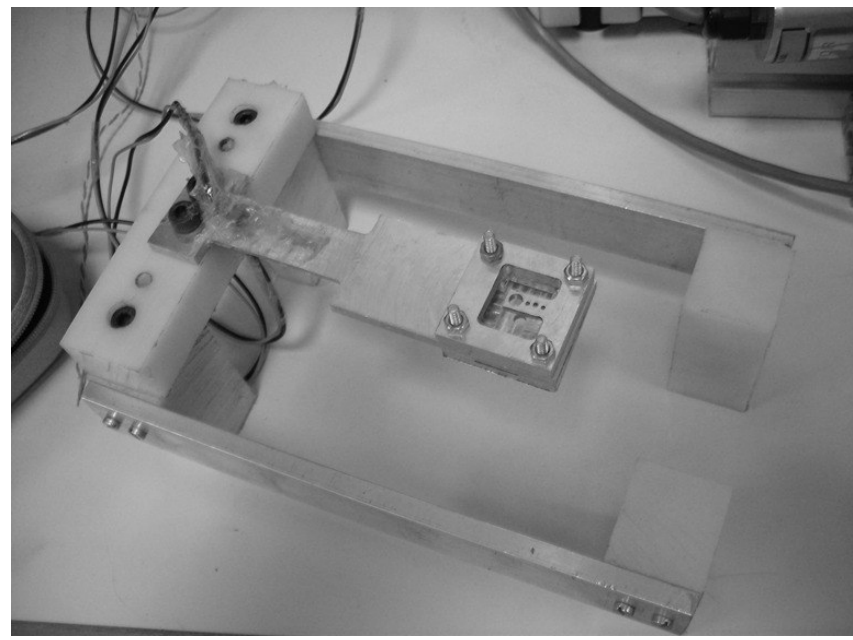

Fig. 3. Picture of cantilever beam tissue holder and strain gauge arrangement.

\section{Tissue Preparation}

Approximately $150 \mathrm{~mm}$ length of porcine aortic tissue was harvested, refrigerated and prepared for testing less than 24 hours after death. A single aortic section was cut into twelve sample sizes of $5 \mathrm{~mm} \times 20 \mathrm{~mm}$. Connective tissue was also removed from arteries outer wall. The tissue was stored in a saline solution at $37^{\circ} \mathrm{C}$ for approximately one hour prior to testing.

\section{Experimental Protocol}

To test the force required to perforate the arterial tissue in vitro, the $1.0 \mathrm{~mm}$ diameter waveguide was advanced through the samples (at $37^{\circ} \mathrm{C}$ ) both with and without ultrasonic activation. All experiments were conducted with a constant feed-rate of $0.5 \mathrm{~mm} / \mathrm{s}$.

For the experiments with ultrasonic waveguide activation the ultrasound was operated in continuous mode at $22.5 \mathrm{kHz}$. 
Three different power settings were tested corresponding to distal-tip displacements of 32, 50 and $80 \mu \mathrm{m}$ p-p.

\section{RESUlTS AND DISCUSSION}

A total of 12 porcine aorta tissue samples were tested. Three samples were subjected to perforation with no ultrasonic energy applied to the waveguide and nine samples (three per power setting level) with the ultrasonic activation.

Figure 4 shows examples of the experimental perforation profiles achieved for the waveguide with no ultrasound activation and for the three power settings. The results show a two stage penetration, both with and without ultrasound. This may be associated with the composition of the aortic lumen, namely the two structural layers of varying elasticity (intima-media and adventitia).

The curves may be described as follows:

a) An initial rise in force as the wire wave-guide contacts the sample.

b) Peak 1: This initial maximum peak force is thought to represent perforation of the intima-media layer (samples were set-up so the internal arterial wall was penetrated, simulating the in vivo scenario).

c) A secondary rise in force as the waveguide contacts the adventitia layer.

d) Peak 2: Perforation of the adventitia layer and an associated reduction in force to a negligible value.

It is also possible to see that when the waveguide is not activated, there is a net reactive force on the waveguide after perforation due to friction with the tissue. This force appears to be less in the tests with the ultrasound applied.

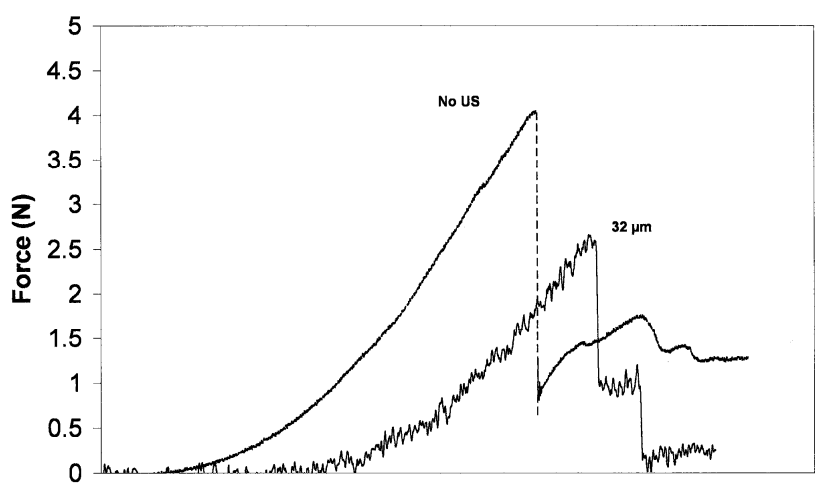

Fig. 4. Penetration force profiles, with no ultrasound applied (No US) and for an ultrasonic wire waveguide distal-tip displacement of $32 \mu \mathrm{m}$ peak-to-peak. Waveguide feed-rate $=0.5 \mathrm{~mm} / \mathrm{s}$.

The increase in ultrasonic power to the wire waveguide and therefore increased distal-tip displacements resulted in a lower force required to perforate both the intima-media layer and the adventitia. The results of the maximum penetration force in all 12 experiments are shown in Figure 5.

The average maximum force (Newtons) required for perforation with ultrasound is approximately $30 \%(3.96 \mathrm{~N}$ vs. $2.67 \mathrm{~N}$ ) less than without ultrasound at the lowest ultrasonic power setting $(32 \mu \mathrm{m} \mathrm{p}-\mathrm{p})$. With no ultrasound activation, it was found that a force exceeding $3.8 \mathrm{~N}$ resulted in perforation of the healthy arterial tissue with the $1 \mathrm{~mm}$ rounded waveguide distal-tip, while at ultrasonic energy levels of $80 \mu \mathrm{m}$ p-p this was reduced to approximately $2 \mathrm{~N}$.

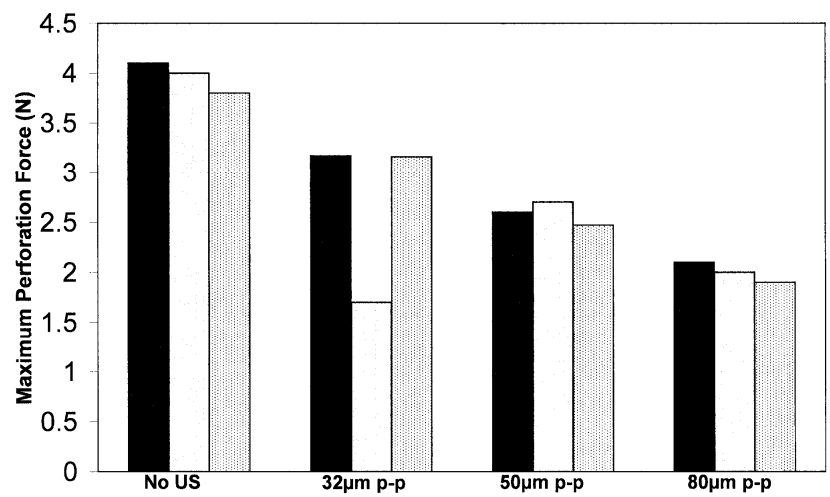

Fig. 5. Maximum penetration force (through intima-media layer) with no ultrasound applied (No US) and for ultrasonic wire waveguide distal-tip displacement of 32, 50 and $80 \mu \mathrm{m}$ peak-to-peak. All 12 tissue tests shown. Waveguide feed-rate $=0.5 \mathrm{~mm} / \mathrm{s}$.

\section{CONCLUSIONS}

Chronic total occlusions are associated with increased complications, including incidence of arterial perforation due to their geometrical and mechanical composition. As a result, they often require more aggressive strategies. Therapeutic ultrasound angioplasty has been shown to be effective in the removal of fibrous and calcified plaques. Increases in distaltip displacements have also been shown to increase removal rates of the diseased tissues, particularly calcified plaques.

This study indicates that at the displacements required to effectively remove diseased tissue, there may be an associated reduction in the force required to cause perforation of the healthy arterial wall. For the experiments outlined above, the angle of incidence of the waveguide is 90 degrees and may not be entirely representative of the in vivo situation where lower contact angles are more probable from waveguide deflection off the lumen axis. Also, the diameter of wire used in this study is greater than those reported in the literature for arterial access and is, therefore, more rigid.

Incidence of arterial perforation still occur, however, with highly flexible guidewires and devices and the results presented here show that with ultrasonic activation the force required to cause perforation may be reduced further.

These results may prove useful in determining optimum operating powers for safe selective tissue removal, while reducing the likelihood of arterial perforation. 


\section{REFERENCES}

[1] WHO, Cardiovascular Diseases: Fact sheet No. 317, World Health Organization, Published: February 2007.

[2] N.V. Salunke and L.D. Topoleski, "Biomechanics of atherosclerotic plaque", Critical Reviews in Biomedical Engineering, vol. 25, 1997, pp. 243-285.

[3] M. DeWood et al, , "Prevalence of total coronary occlusion during the early hours of transmural myocardial infarction", N. Eng. J. Med, vol. 303, 1980, pp. 897-902.

[4] G.W. Stone et al, "Percutaneous recanalization of chronically occluded coronary arteries", Circulation, vol. 112, 2005, pp. 23642372.

[5] G.G. Hartnell, J.M. Saxton, S.E Friedl, G.S. Abela and U. Rosenschein "Ultrasonic thrombus ablation: In vitro assessment of a novel device for intracoronary use", Journal of Invasive Cardiology, vol. 6, pp. 69-76, 1993 .

[6] P.J. Fitzgerald and P.G. Yock, "Catheter-based ultrasound thrombolysis, shake, rattle and reperfuse", Circulation, vol. 95, pp. 1360-1362, 1997.

[7] T. S. Etsuo Tsuchikane et al "Debulking of chronic coronary total occlusions with rotational or directional atheretomy before stenting, final results of doctors study", International Journal of Cardiology, vol. 125 , pp. $397-403,2008$

[8] G. J. Siegal et al, "Use of therapeutic ultrasound in percutaneous coronary angioplasty: experimental in vitro studies and initial clinical experience", Circulation, vol. 89, pp. 1587-1592, 1994.

[9] Flowcardia press release, "Clearance for the CROSSER 14 chronic total occlusion recanalization system", January $23^{\text {rd }} 2007$

[10] W. Steffen., R. J. Siegal, "Ultrasound angioplasty - a review", Cardiol, vol. 6, pp. 77-88, 1993

[11] I. R. Makin. and E. C. Everbach, "Measurement of pressure and assessment of cavitation for a $22.5-\mathrm{kHz}$ intra-arterial angioplasty device", Acc Soc Am, 1996.

[12] U. Rosenschein, A. Frimerman , S. Laniado and H.I. Miller. "Study of the mechanism of ultrasound angioplasty from human thrombi and bovine aorta ", Am J Cardiol., vol. 74, pp. 1263-6, 1994.

[13] M. Chikada, "An experimental study of surgical ultrasonic angioplasty: Its effect on atherosclerosis and normal arteries", Ann Thorac. Surg, vol. 77, 2004, pp. 243-6.

[14] G.P. Gavin, G.B. McGuinness, F. Dolan and M.S.J. Hashmi, "Performance characteristics of a therapeutic ultrasound wire waveguide apparatus", International Journal of Mechanical Sciences, vol. 49 (3), 2007, pp. 298-305.

[15] D. Noone, G.P. Gavin and G.B. McGuinness, "Design issues for therapeutic ultrasound angioplasty waveguides", proceedings of the $25^{\text {th }}$ International Manufacturing Conference, 2008, Dublin, Ireland 